\title{
Work in Progress - Classical Ballet Structure and Practice Applied to Engineering Class Sessions
}

\author{
Blair London ${ }^{1}$, Lisa Deyo ${ }^{2}$
}

\begin{abstract}
Classical ballet classes have a universal structure that fosters active in-class learning. This structure creates a safe environment for students to try, fail, be corrected, and succeed. Engineering classes lack a common structure; most learning in engineering occurs outside of class. Engineering classes could move toward adopting a similar structure to ballet to improve in-class learning and mirror engineering culture and practice. The paper describes aspects of ballet class structure and practices that work and how these can apply to engineering classes. A new engineering class session structure is presented following the ballet model where engineering students are motivated to participate and learn during the class.
\end{abstract}

Index Terms - Active learning, Ballet instruction, Engineering class structure, Motivation for learning.

\section{INTRODUCTION}

Outstanding professional ballet dancers are produced because of the learning that occurs in classical ballet class. Engineering professionals are produced in spite of their undergraduate engineering classes. Even in the age of problem-based and activity-based learning methods [1, 2], most engineering classes do not engender a high level of student engagement and learning during class sessions. This is not the case with classical ballet instruction where the structure, activities, and culture of the class foster learning. By applying many of the tested techniques in ballet class we can improve engineering classes.

\section{Ballet Class Structure}

Every classical ballet class has the same structure and organization: beginning exercises with the support of the barre, advancing to more challenging movements in the center, and a formal closing known as reverence. Movement progresses from basic to advanced, slow to fast, and small to large. This structure has been used for over 300 years [3] with great success, and most students have an awareness of this context in ballet history. Students appreciate what has preceded; they anticipate what will come, and they are eager to contribute in class. Student engagement is immediate and constant.

The non-negotiable rigidity of the class structure is reassuring. Students know there will be parts they will enjoy and parts that they will not - both exist and neither lasts long.
Knowing what to expect by a consistent structure creates a sense of mastery and control. This allows the students to venture more risk. The confines of class form a safe environment within which to be creative and excel. It even makes most ballet classes "teacher-proof" where it is possible to have a good class with a poor teacher so long as the structure of the traditional class is maintained. Ballet students can always get something out of class because the student mindset is not "what can this instructor do for me?", but "what will I discover that will help me?" It is the student's personal quest for excellence.

There is reassurance that class is not a performance. Class is the time to fall; to push physical and mental boundaries; to develop strength, agility, and stamina. The goal is that when an actual performance arrives, students may be relaxed, confident, prepared, and eager to demonstrate their skills.

There is a continuous back-and-forth between learning and doing (Figure 1). There are multiple opportunities for trial and error with feedback. In essence, class represents structured, supervised, and critiqued practice.

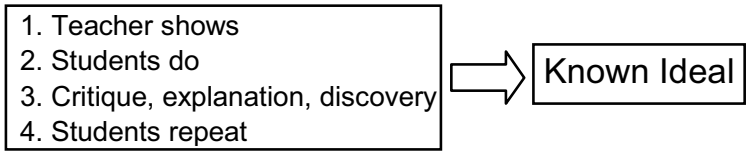

FIGURE 1

TEACHING PATTERN OF A TYPICAL BALLET CLASS.

Ballet students are constantly on a quest for a known ideal - the execution of a certain step, the attainment of a certain line. Ballet students know what they are trying to achieve, and their fleeting glimpses of this in their movements are a powerful motivational force in class. In addition, ballet students are not just judged by the teacher, but by other students, which can be even more important. This creates an environment of constant public accountability and competition. Students are always "on", they cannot "hide". Classical ballet instruction works (Figure 2).

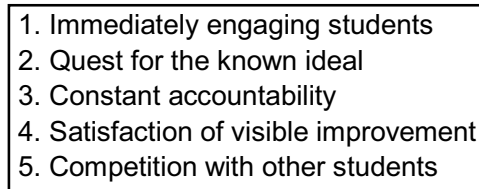

FIGURE 2

WHAT WORKS ABOUT BALLET CLASS.

\footnotetext{
${ }^{1}$ Blair London, Professor, Materials Engineering Department, California Polytechnic State University, San Luis Obispo, CA, blondon@calpoly.edu

${ }^{2}$ Lisa Deyo, Professional Dancer, Choreographer, and Dance Teacher, San Luis Obispo, CA, jildeyo@deyodances.com 


\section{Engineering Class Structure}

Engineering classes could greatly benefit from a common, rigid structure following the ballet model. While engineering education has produced functioning engineering professionals, the traditional methods of achieving those educational goals are flawed (Figure 3). The vast majority of engineering classes are still solely lecture [4], which leads to little in-class learning [5]. Most of the learning comes from students solving assigned problems outside of class. The model is one of delayed learning which produces little mastery, no control, and low self-confidence. Actual engineering practice is not like this where many decisions are made in a concurrent fashion, and mastery and creativity are the hallmarks of outstanding engineering.

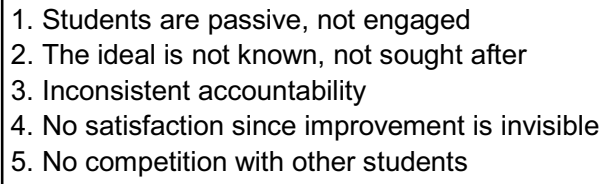

FIGURE 3

WHAT DOES NOT WORK IN ENGINEERING CLASS.

The engineering class structure needs to support an active learning mode and follow the supervised, structured, and critiqued practice proven to work in ballet. Engineering students would still need to solve problems outside of class. However, a new class structure promoting learn-in-themoment modes will motivate students to want to solve those problems on their own as they gain true mastery of engineering and seek a known ideal of performance (Figure 4). The excitement that originally attracted our students to engineering to do amazing things and change the world would be empowered, not quashed.

The class session (not lecture) starts right away with a 5-7 minute Beginning Activity - a problem to solve, an explanation to make. The students are immediately active and engaged in class, and there is no time to "settle in" at their seats waiting for a lecture. Next comes the Historical Context of the topics to follow in the session. Everything in engineering had a beginning: a famous experiment, a new idea, a radical design. Making these connections for students provides a sense of context and teaches the culture of engineering. It also begins to uncover the known ideal - what students can strive to achieve in their careers, i.e., "they changed the world, so can you". This is a "window" to show engineering students the mysteries that will be unlocked for them in class and then the powers and tools they will have acquired by mastering them.

The next part of the class is New Topics \& Concepts where new information is presented in a relatively short lecture-type mode. A vital part of the New Topics section is a Demonstration which can be a physical demonstration or a worked problem. Following the mini-lecture, the students work on an Activity (individually or in small groups) designed
Session F1E

\begin{tabular}{|c|c|}
\hline Beginning Activity & Historical Context \\
\hline \multicolumn{2}{|c|}{ New Topics \& Concepts } \\
\cline { 2 - 2 } & Demonstration \\
\hline Activity & $\begin{array}{l}\text { Activity } \\
\text { Critique }\end{array}$ \\
\hline \multicolumn{2}{|c|}{ Engineering Links } \\
\hline Concept Round-Up & Closing \\
\hline
\end{tabular}

FIGURE 4

PROPOSED STRUCTURE OF AN ENGINEERING CLASS SESSION.

by the instructor to use the new material just covered. The instructor can Critique the student's performance on the Activity following, or during, their solution time. Here is the structured, supervised, and critiqued practice that works in ballet classes. Competition in the same group can motivate students to a higher level of performance in class; making this activity public between groups is even better. As in ballet class, engineering students know that the class is not the exam or their job; rather, a safe environment to try new things. The class then turns to a group of problems commonly called homework, but now referred to as Engineering Links. The problems are briefly discussed as further opportunities for students to apply the concepts and topics of the class session. The class structure is now designed so that students want to solve these problems because they are the connections to real engineering and applications. The Concept Round-Up is a reiteration of the main concepts of the day; the repetition is valuable for true retention. The session ends with a formalized Closing, which is similar to the reverence in ballet class. This acts to reinforce the formal nature of class and place a proper ending on an effective class session.

The goal of the new structure for engineering classes is not that students will necessarily want to attend class; rather, that they sincerely want and know the value of what they can get out of class.

\section{REFERENCES}

[1] Felder, R. M., and Brent, R., "Learn by Doing", Chemical Engineering Education, 37(4), 2003, pp. 282-283.

[2] Johnson, D.W., Johnson R.T., and Smith, K.A., Active Learning: Cooperation in the College Classroom, 2nd Ed., Edina, MN, Interaction Book Company, 1998.

[3] Hammond, S. N, Ballet Basics, (4 ${ }^{\text {th }}$ Ed.) Mountain View, Mayfield Publishing Co., 2000, pp. 138-161.

[4] Student Focus Groups, Cal Poly State University, San Luis Obispo, CA, April, 2004.

[5] McKeachie W.J. et al., Teaching and Learning in the College Classroom: A Review of the Research Literature ( $2^{\text {nd }}$ Ed.), Ann Arbor, University of Michigan, 1990. 